\title{
CHEMISTRY AND LIGHT - PART 2: LIGHT AND ENERGY*
}

Franco Scandola, Carlo Alberto Bignozzi

Dipartimento di Chimica - Università di Ferrara - Via L. Borsari, 46 - 44100 - Ferrara - Itália

Vincenzo Balzani

Dipartimento di Chimica "G. Ciamician” - Università di Bologna - Vila Selmi, 2 - 40126 - Bologna - Itália

Recebido em 19/8/96

\begin{abstract}
The conversion of solar energy into more useful forms of energy, such as chemical fuels or electricity, is one of the central problems facing modern science. Progress in photochemistry and chemical synthesis has led to a point where light energy conversion by means of artificial molecular devices can be rationally attempted. In this article, a general approach towards this challenging goal is presented.
\end{abstract}

Keywords: photochemistry; light; energy.

Life is a water mill: the effect produced by the falling water is achieved by the rays of the sun. Without the sun the wheel of life cannot be kept going. But we have to investigate more closely which circumstances and laws of nature bring about this remarkable transformation of the sunrays into food and warmth.

W. Ostwald: Die Mühle des Lebens, Thomas, Leipzig (1911)

\section{INTRODUCTION}

Light is made of photons, and photons are at the same time energy quanta and information bits. Accordingly, most processes involving the interaction of light with matter (in a general sense, "photochemical processes") can be distinguished according to the predominant energy-carrying or informationcarrying role of photons. Living examples of this double-faced nature of light are provided by the two most important photochemical processes taking place in the biological world, photosynthesis and vision.

As pointed out in a previous article of this series ( $L a$ Chimica e l'Industria 1995, 77, 24)**, photochemistry is nowadays a well-established and developed research field. The progress in photochemistry, together with that in chemical synthesis, has led to the point where one can conceive artificial photochemical molecular devices capable of using light as an energy supply (to sustain energy-expensive functions) or as an input signal (to be processed and/or stored). In this article, we will try to outline a rational approach to the design of artificial systems of the first kind, in particular for the conversion of light energy into chemical or electrical energy.

\section{LEARNING FROM PHOTOSYNTHESIS}

Photosynthesis is the basic process by which, under the action of sunlight, living organisms convert abundant low-energy substrates into valuable chemicals of high free energy content (biological fuels). In green plant photosynthesis, the reaction is the conversion of water and carbon dioxide into oxygen and carbohydrates (eq. 1).

$\mathrm{H}_{2} \mathrm{O}+\mathrm{CO}_{2}+\mathrm{hv} \rightarrow \mathrm{O}_{2}+1 / 6\left(\mathrm{C}_{6} \mathrm{H}_{12} \mathrm{O}_{6}\right)$

This is certainly the most important process for life on our planet. From a purely biological viewpoint, it represents a

\footnotetext{
* Publicado em La Chimica e l'Industria 1995, 77, 959

** Quim. Nova 1996, 19, 542
}

continuous supply of two absolutely vital goods: atmospheric oxygen and the organic material that supports the food chain. On the other hand, photosynthesis is also very important for human civilization, as it is responsible for the accumulation of huge amounts of fossil fuels. Reaction 1 is highly endoergonic (as much as $114 \mathrm{kcal} / \mathrm{mol}$ can be obtained from the opposite "combustion" reaction) and can only be obtained thanks to the energy input of the incoming photons. Photosynthetic systems are present mainly in green plants, but also in other organisms such as algae and bacteria ${ }^{1}$. The general structure of the photosynthetic machine present in the tilakoyd membrane of green plants is schematically shown in Fig.1. The global function of this complex device is the oxidation of water to oxygen on the internal side and the reduction of $\mathrm{NADP}^{+}$to NADPH (which

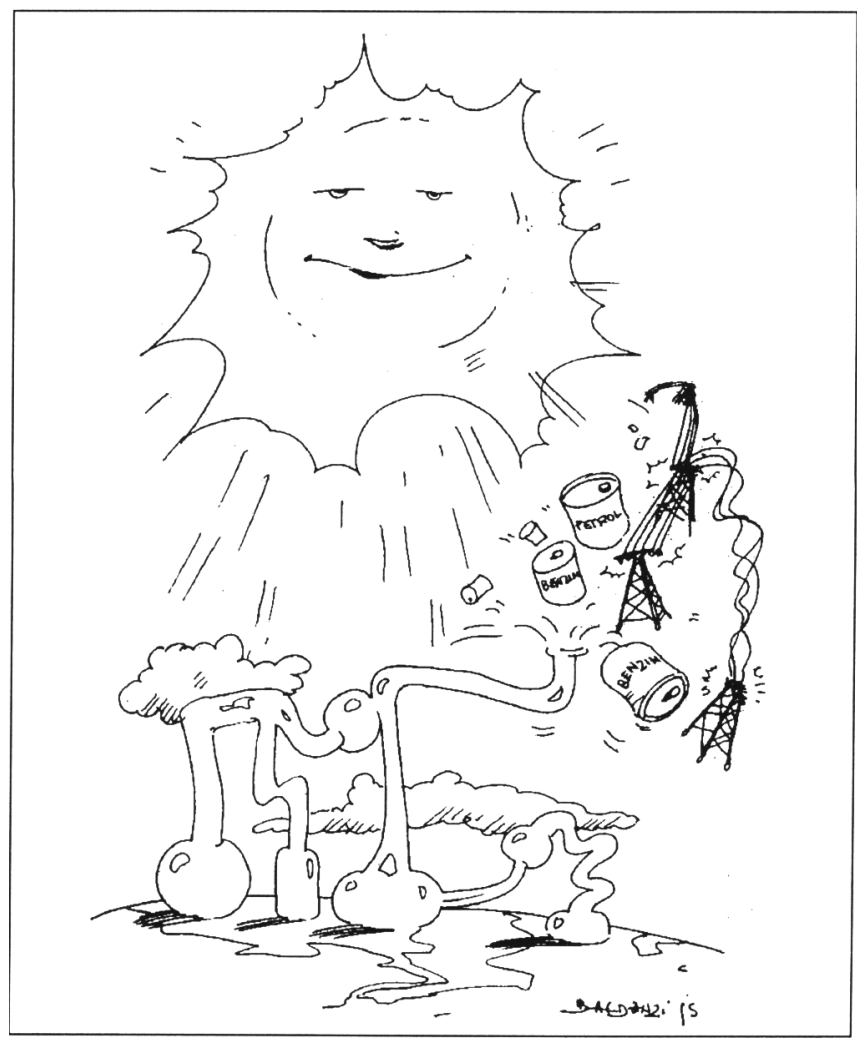




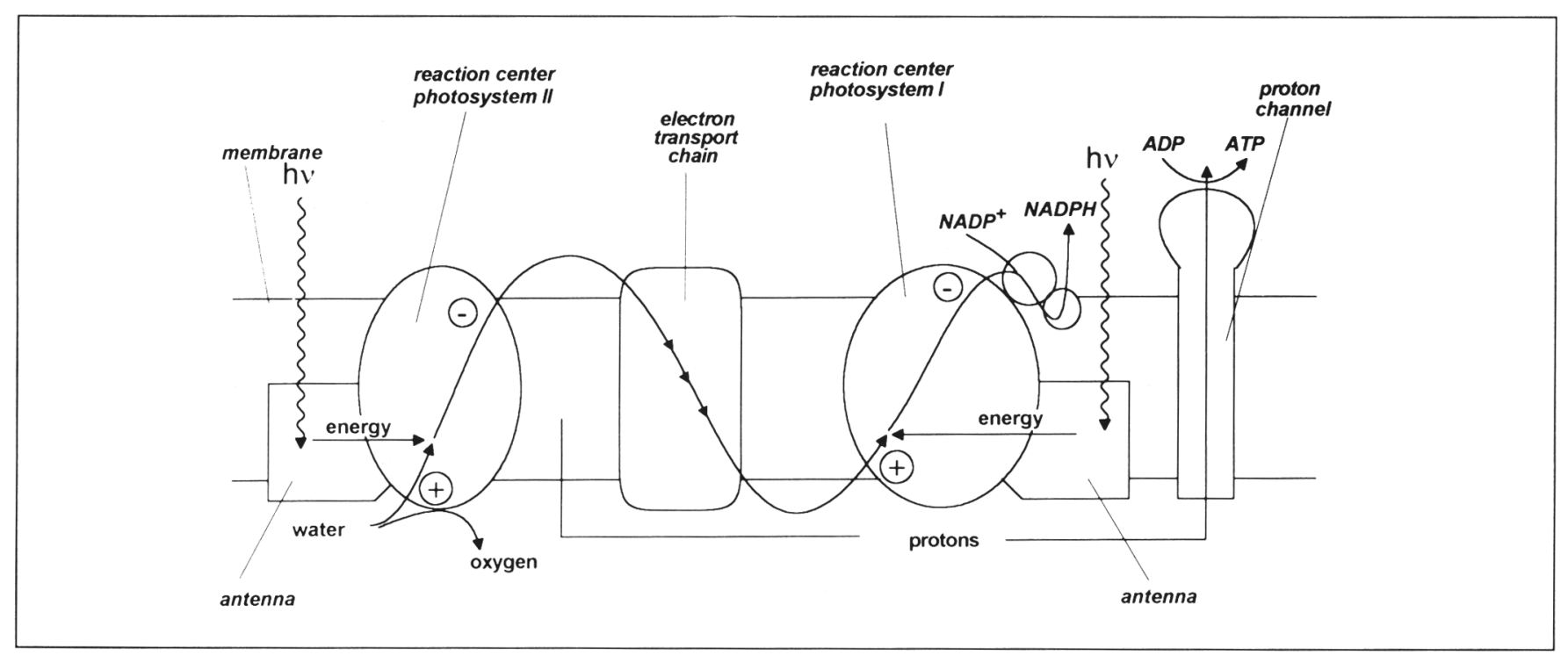

Figure 1. Schematic representation of the photosynthetic process in green plants.

will be used later for the synthesis of carbohydrates from carbon dioxide, see the Inset) on the external side of the membrane. To reach this goal, the photosynthetic membrane contains several protein complexes (schematized by contour lines), each of which performs a specific function. Among these, the most important are the so-called reaction centers, usually designated as "photosystems I and II", which completely span the membrane. The function of each of these photosystems is to generate, following light absorption, a pair of charges of opposite sign on opposite sides of the photosynthetic membrane, a process usually indicated as "photoinduced charge separation". The positive hole generated in photosystem II is used with the help of a manganese-containing enzyme, for the oxidation of water. The negative charge developed by photosystem I is used, with the intermediacy of suitable proteins, in the reduction of $\mathrm{NADP}^{+}$. The components lying between the two photosystems have the role to connect "in series" photosystems I and II, i.e., to allow the electron-transfer processes by which the negative charge developed by photosystem II neutralizes the positive charge developed by photosystem I. As an additional useful function, the photosynthetic membrane synthetizes ATP (another high-energy chemical to be used in the synthesis of carbohydrates) taking advantage of the proton concentration gradient created by the photochemical oxidation and reduction reactions (see the Inset).

Interestingly, excitation does not involve direct light absorption by the two photosystems, but energy transfer from the socalled light harvesting antenna systems. One of such systems is placed close to each of reaction centers (Fig. 1). The antenna systems contain a large number (hundreds) of chromophores and have thus a much larger cross section for light absorption than the reaction centers. Indirect excitation of the reaction center through the antenna is the way chosen by Nature to solve the problem of light-harvesting efficiency with a relatively small number of reaction centers in low-intensity illumination conditions.

Even from a simplified block-type description such as that of Fig. 1, it is apparent that the photosynthetic machinery of green plants is a very complex one. This is not surprising, given the complex nature of the overall chemical process to be achieved. From the simple viewpoint of energy conversion, however, two fundamental functions can be extracted from the analysis of this complicated machine: (i) photoinduced charge separation, and (ii) antenna effect. A closer inspection at the structure of reaction centers and antenna systems may be

\section{Photosynthesis and the Nobel Prize in Chemistry}

The understanding of natural photosynthesis is one of the most prominent achievements of modern chemistry, as witnessed by the award of several recent Nobel Prizes in Chemistry within this field of research.

In 1961 Melvin Calvin received the Nobel Prize for his unravelling of the complex cycle (known as Calvin cycle) which, in green plants, uses the energy stored in the primary products of the photosynthetic process (NADPH, ATP) to effect the reduction of carbon dioxide to carbohydrates.

In 1978 Peter Mitchell received the Nobel Prize for the "chemiosmotic theory", which accounts for the synthesis of ATP in terms of the proton gradient created across the membrane by the photochemical water oxidation and $\mathrm{NADP}^{+}$reduction.

In 1988, Johan Deisenhofer, Robert Huber, and Hartmut Michel received the Nobel Prize for the crystallization and determination of the X-ray structure of the reaction center of Rhodopseudomonas viridis. Among other outstanding aspects of their discovery, the precise knowledge about the spatial arrangement of the active molecular components of the reaction center represented a real breakthrough in the field, opening the possibility of a detailed understanding of the charge separation mechanism in terms of the kinetics of the various electron-transfer steps.

The theoretical basis for the understanding of electron-transfer processes had been laid down by Rudolph A. Marcus in the late sixties. To reach conclusive experimental confirmation and general acceptance, however, the Marcus theory had to wait recent years, with the advent of fast and ultrafast kinetic methods to study reactions taking place in pico- $\left(10^{-12}\right)$ and femto- $\left(10^{-15}\right)$ seconds. In particular, it is now recognized that the main reason for the extraordinary efficiency of the charge separation taking place in natural photosynthesis in the fact that the various charge recombination steps belong to the so-called Marcus "inverted" kinetic regime, where highly exergonic electrontransfer reactions, contrary to common expectations, were predicted by Marcus to be intrinsically slow. The importance of this theoretical model as a tool for prediction and rationalization of electron-transfer rates was acknowledged with the award to its author of the 1992 Nobe Prize in Chemistry. 
useful to highlight the relationship between function and structure in natural photosynthesis.

\subsection{Charge separation in reactions centers}

A giant step in the understanding of photoinduced charge separation has been made with the determination by X-ray crystallography of the structure at the molecular level of some reaction centers ${ }^{2-6}$ (see the Inset). These structure determinations refer to bacterial, rather than green plant, photosynthesis but the basic features are likely very similar in all cases. A simplified view of the structure of the reaction center of Rhodopseudomonas viridis ${ }^{2,5,6}$ is sketched in Fig. 2. Detailed photophysical studies of this reaction center have led to a precise picture of the sequence of events participating in photoinduced charge separation. The key molecular components are a bacteriochlorophyll "special pair" (P), a bacteriochlorophyll monomer (BC), a bacteriopheophytin (BP), a quinone (Q), and a four-heme ctype cytochrome $(\mathrm{Cy})$. These chromophores are held in a fixed geometry by surrounding proteins that span the photosynthetic membrane, so that the twofold axis of $\mathrm{P}$ is perpendicular to the membrane, the periplasmic face lies approximately between $\mathrm{P}$ and $\mathrm{Cy}$, and the cytoplasmic face at the level of Q. In the reaction center, excitation of $\mathrm{P}$ is followed by very fast (ca. 3 ps) electron transfer to the BP "primary"7-13 acceptor. The next step is fast (ca. $200 \mathrm{ps}$ ) electron transfer from $\mathrm{BP}$ to $\mathrm{Q}^{14}$, followed by slower (ca. $270 \mathrm{~ns}$ ) reduction of the oxidized $\mathrm{P}$ by the nearest heme group of $\mathrm{Cy}^{15}$. At that stage, transmembrane charge separation has been achieved with an efficiency approaching unity and an extremely long lifetime with respect to charge recombination.



Figure 2. Schematic view of the reaction center of Rhodopseudomonas viridis 5 .

Figure 2 points out the importance of the supramolecular structure of the reaction center. The achievement of efficient photoinduced charge separation over a large distance is made possible by optimization of several aspects of this photochemical device: (i) the organization of the molecular components in space, (ii) the thermodynamic driving force of the various electron-transfer steps, (iii) the kinetic competition between forward (useful) over back (dissipative) electrontransfer processes. How this comes about can be reasonably understood in terms of modern electron-transfer theory ${ }^{16-20}$ (see the Inset).

\subsection{Energy migration in antena systems}

As far as the antenna units are concerned, detailed structural information has become available only very recently, when high resolution structures of some light-harvesting complexes of green plant and bacterial photosynthesis have been reported $^{21-24}$. Figure 3 gives a very schematic picture of the socalled LH2 complex of the Rhodopseudomonas acidophila bacterium. It has a beautifully symmetric structure, built upon 18 transmembrane helical proteins (schematically indicated in Fig. 3 by vertical rods) arranged in two concentric cylinders: 9 identical $\alpha$-proteins in the inner hollow cylinder (radius, $18 \AA$ ), and 9 identical $\beta$-proteins in the outer one (radius, $34 \AA$ ). A total of 27 chlorophyll molecules (schematically indicated in Fig. 3 as planar sheets) is held within this protein assembly. These chlorophylls are linked to the proteins by axial coordination of the magnesium atom and form two distinct groups. There are 18 molecules, linked alternately to the $\alpha$ - and $\beta$ proteins via histidine residues, that lie parallel to the nine-fold symmetry axis (i.e., perpendicular to the membrane plane) and constitute a cylindrical arrangement lying between the two protein walls, with their centers at about $10 \AA$ from the top (presumed periplasmic membrane surface). In addition, 9 chlorophyll molecules, linked to the $\alpha$-proteins via the terminal formylmethionine group, lie on a plane perpendicular to the ninefold symmetry axis (i.e., parallel to the membrane plane), between pairs of $\beta$-protein columns, a further $16.5 \AA$ down into the membrane. Because of the different environments, the two types of chlorophyll molecules have different absorption spectra and excited-state energies. Besides the chlorophyll chromophores, the antenna complex contains also nine carotenoids, not shown in Fig. 3, which span the membrane in an extended conformation between the two protein walls, and make van der Waals contacts with both types of chlorophyll molecules ${ }^{21}$. The energy flow within the LH2 complex is determined by the energy levels of the three types of chromophores, which are in the order carotenoids >

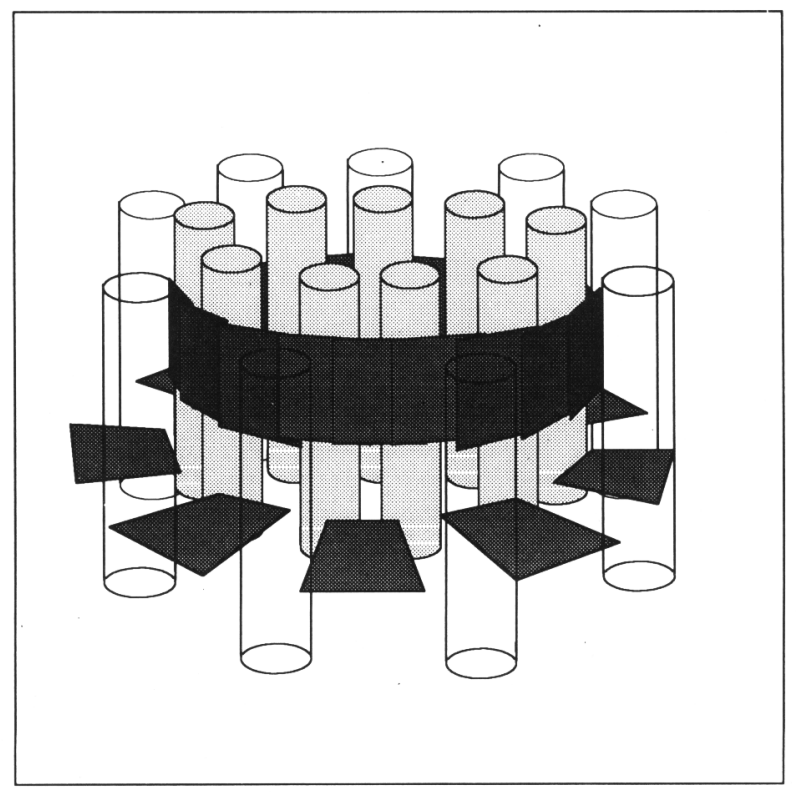

Figure 3. Schematic representation of the structure of the LH2 antenna complex of Rhodopseudomonas acidophila. Apoprotein helices are indicated by rods, chlorophyll molecules are depicted as planar sheets. 
horizontal chlorophylls > axial chlorophylls. The ring of axial chlorophylls acts then as a "storage ring" for the energy, before it is transferred to the reaction center.

This transfer does not occur directly, but with the intermediacy of another type of antenna complex, called LH1. The LH1 complex has most probably ${ }^{23}$ the same basic structure as LH2, except for the larger dimensions: 16 proteins (instead of 9) for each ring in the columnar structure, and a correspondingly higher number of chromophores in the same general arrangement. The relative positioning of the various units within the photosynthetic membrane is presumably as shown schematically in Figure 4, with the two types of antenna complexes in contact, and with the LH1 complex hosting the reaction center within its inner cavity $^{22}$. The excited-state energy of the chlorophyll molecules of the larger "storage ring" (LH1) is lower than that of the chlorophyll molecules of the smaller one (LH2), and slightly higher than that of the special pair in the reaction center. The overall energy flow taking place within this wonderful supramolecular machine is schematized in Figure 4.

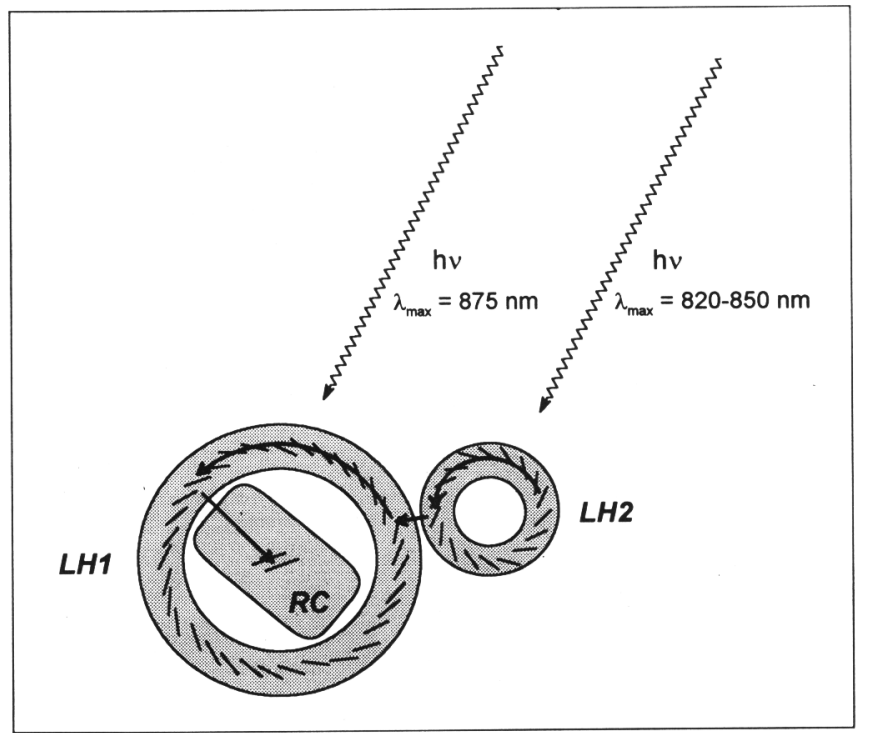

Figure 4. Plausible structural relationship between the antenna complexes and the reaction center of bacterial photosynthesis, and energy-flow pathway involving these units.

\section{ARTIFICIAL SYSTEMS FOR ENERGY CONVERSION}

The complexity of the natural photosynthetic systems is clearly out of reach for the synthetic chemist. This complexity, however, is largely related to their living nature and it is entirely plausible that single, simple functions similar to those found in Nature, such as, e.g., the antenna effect and photoinduced charge separation, can be duplicated by relatively simple artificial supramolecular systems. The lesson from Nature is that the achievement of such function requires a supramolecular structure with very precise organization in the dimensions of space (molecular components), energy (excited states and redox potentials), and time (elementary acts). Organization, which in the natural systems comes as a result of evolution, can be imposed in artificial systems by molecular engineering. Some examples of artificial systems built along such guidelines are given in the following sections.

\subsection{Charge separation in artificial multicomponent systems}

As shown by natural photosynthesis, long-lived photoinduce charge separation can be obtained by an appropriate sequence of electron-transfer processes following photoexcitation. Thus the simplest artificial systems capable of performing such type of process are covalently-linked three-component systems ("triads"). A possible scheme for a charge separating triad is shown in Figure 5. The functioning principle is shown in an orbitaltype energy diagram in the lower part of the Figure. Excitation (1) of a chromophoric component $(\mathrm{P})$ is followed by primary electron transfer (2) to an acceptor (A). This is followed by secondary electron transfer (3) from a donor (D) to the oxidized chromophoric component. The primary process competes with excited-state deactivation (4), while the secondary process competes with primary charge recombination (5).In the absence of fast reactions of the oxidized $\left(\mathrm{D}^{+}\right)$and reduced $\left(\mathrm{A}^{-}\right)$ moieties with external chemical species, charge recombination (6) leads back the triad to its initial state.

Many charge separating triads, made out of both organic and inorganic molecular components, have been made ${ }^{25-33}$. That shown in Figure $6 \mathrm{a}^{31,32}$ makes use of molecular components reminiscent of those found in natural photosynthesis: a porphyrin (playing the role of $\mathrm{P}$ in Fig. 5), a quinone (A in Fig. 5 ), and a carotenoid ( $D$ in Fig. 5). With this triad, the $\mathrm{D}^{+}-\mathrm{P}_{-} \mathrm{A}^{-}$ charge separated state is obtained with a lifetime of $300 \mathrm{~ns}$ and a quantum yield of 0.04 . The efficiency of energy conversion (from absorbed light energy to chemical energy of the charge separated state) is 0.02 . To put things in a real perspective, the "triad portion" of the reaction center of bacterial photosynthesis discussed in section 2 (Fig. 2) gives charge separation with a lifetime of $100 \mathrm{~ms}$ and a quantum yield of 1 , and converts energy with an efficiency of 0.4 .

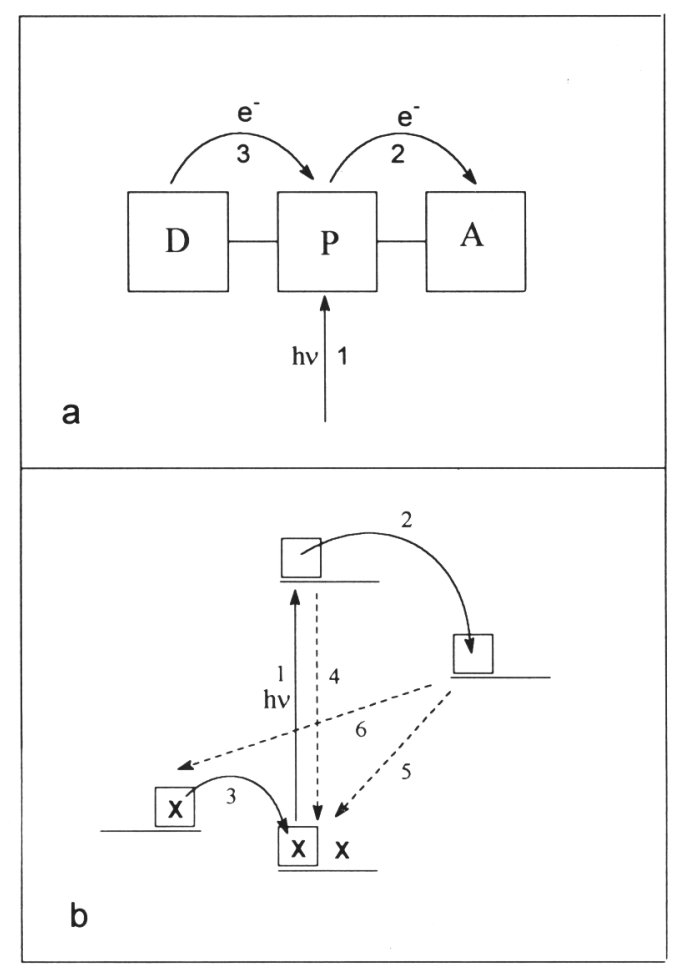

Figure 5. Representation of a "triad" system for photoinduced charge separation as block diagram (a) and energy level diagram (b).

One way to improve the efficiency of charge separation is to increase the complexity of the supramolecular assembly, i.e., by going from triads to tetrads, to pentads, etc.. This strategy can be exemplified by the series of compounds shown in Figure 6 designed by Gust, Moore and their coworkers ${ }^{33}$. The keypoint is the introduction of further molecular components (a secondary acceptor as in $6 \mathrm{~b}$ and $6 \mathrm{c}$, a secondary donor/chromophore as in $6 \mathrm{c}$ ), and thus of further electron transfer steps 


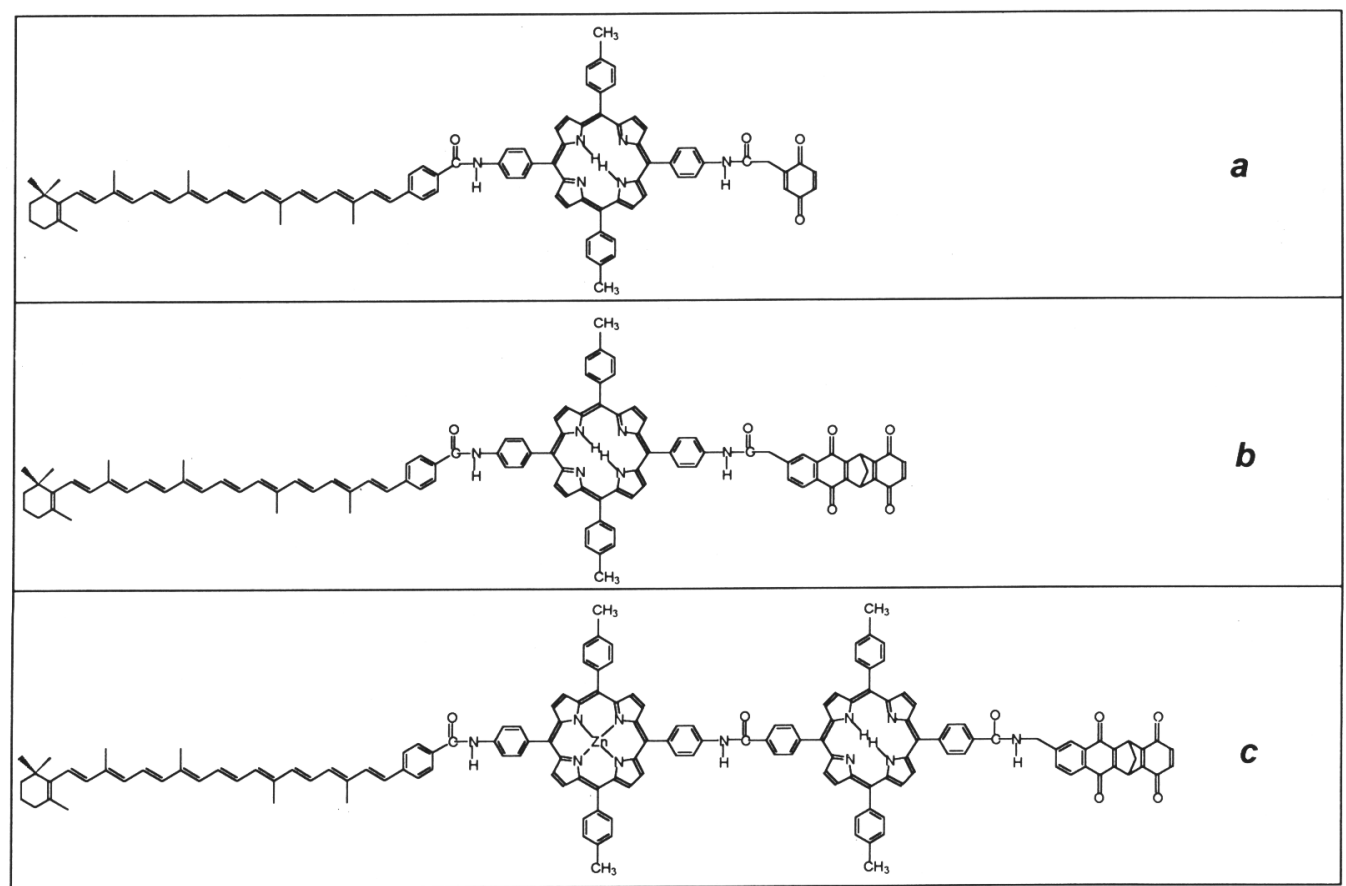

Figure 6. "Triad" (a), "tetrad" (b) and "pentad" (c) systems for photoinduced charge separation based on porphyrins, carotenoids, and quinones as building blocks 33 .

which produce charge separation over larger and larger distances. The improvement in performance with increasing complexity can be seen by comparing the performance of the triad of Figure $6 \mathrm{a}$ with that of the pentad of Figure $6 \mathrm{c}$ : lifetime of charge separation, $55 \mathrm{~ms}$; quantum yield, 0.83 ; energy-conversion efficiency, $0.5^{33}$.

In summary, artificial supramolecular systems for photoinduced charge separation have reached a well-developed stage, approaching in some cases the performance of natural reaction centers. The way towards the use of such molecular devices for practical energy conversion purposes, however, may be still relatively long. Problems and possible applications are discussed in later sections.

\subsection{Artificial antenna systems}

Generally speaking, an artificial antenna is a multicomponent system (Fig.7) in which several chromophoric molecular components (P) absorb the incident light and channel the excitation energy to a common acceptor component (which may be called "reaction center", RC) $)^{34}$.

Porphyrins, the main chromophores of natural photosynthesis, have been the obvious candidates for the design of artificial antenna systems. A pentameric array (Fig. 8) containing a central free-base porphyrin and four peripheral zinc porphyrins (covalently linked to the central one via rigid ethyne bridges), has recently been produced by Lindsey and coworkers ${ }^{35}$. In this system, efficient energy transfer from the peripheral zinc-containing units to the free-base array core was observed. In principle, extension of this type of work towards larger arrays mimicking the natural antenna effect is possible. $\mathrm{Ru}(\mathrm{II})$ and Os(II) tris-bipyridine chromophores have been widely used in the design and synthesis of artificial antenna systems.

An interesting series of polynuclear species of large nuclearity, which because of their shape can be called "dendrimers" or "arborols", has been obtained using Ru(II) and/or Os(II) as metal centers, bis-bipyridine-type ligands as bridging groups, and bipyridine-type terminal ligands ${ }^{36-38}$. Following a modular synthetic strategy known as "complexes-as-metals/complexes-as-

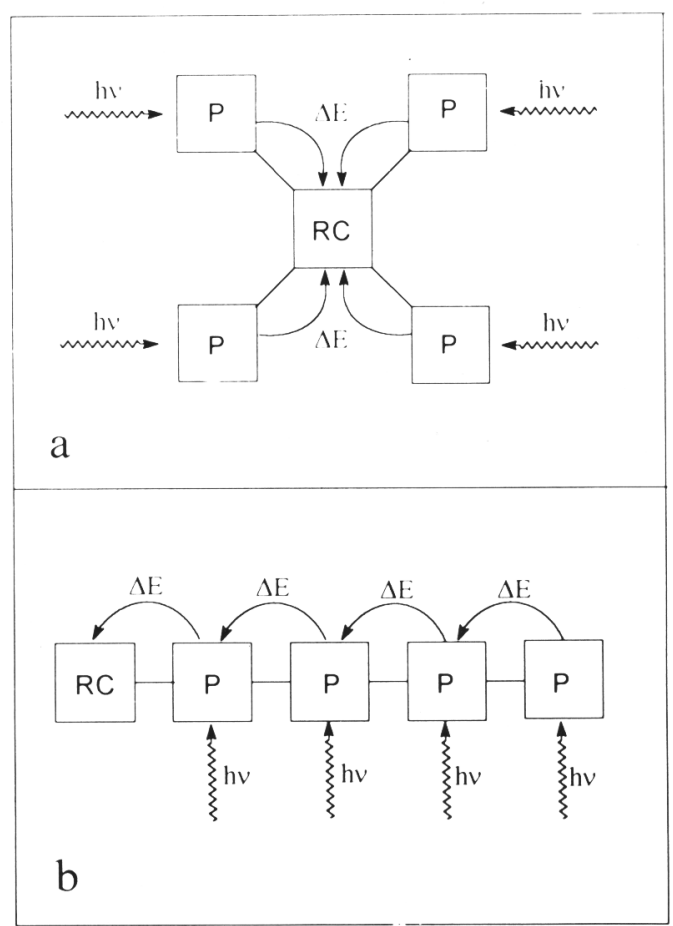

Figure 7. Block-diagram representation of branched (a) and onedimensional (b) antenna systems.

ligands", such polynuclear species can be obtained with a high degree of synthetic control, in terms of the nature and position of metal centers, bridging ligands, and terminal ligands. The energy of the metal-to-ligand charge transfer MLCT excited state of each unit depends on metal and ligands in a well-known and predictable way. Thus, synthetic control translates into control on the direction of energy flow within these molecules. For example, the decanuclear complex shown in Figure $9^{36}$ is made so that the energy absorbed by all the units in the complex flows, 


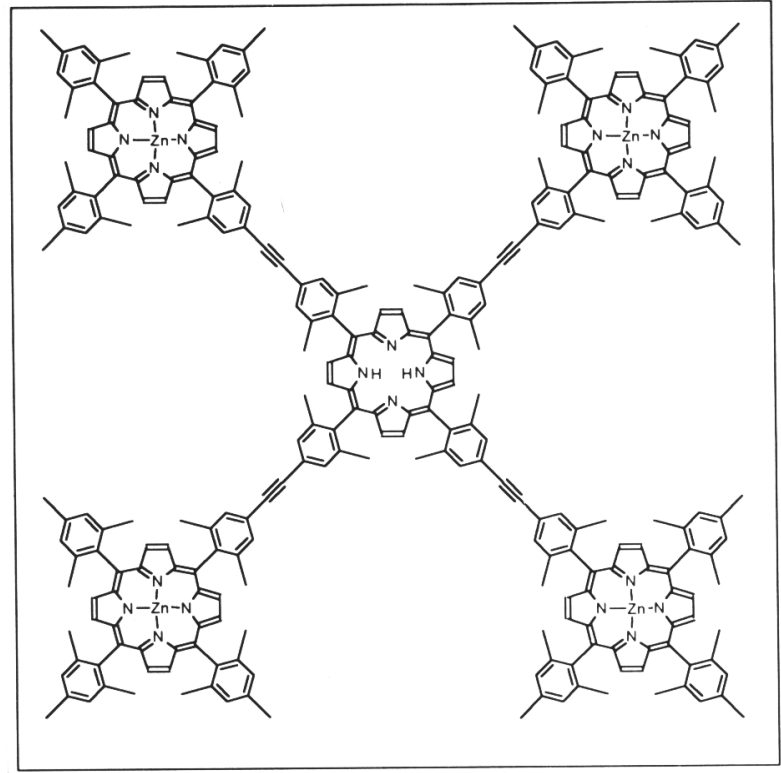

Figure 8. Pentameric porphyrin antenna system ${ }^{35}$.

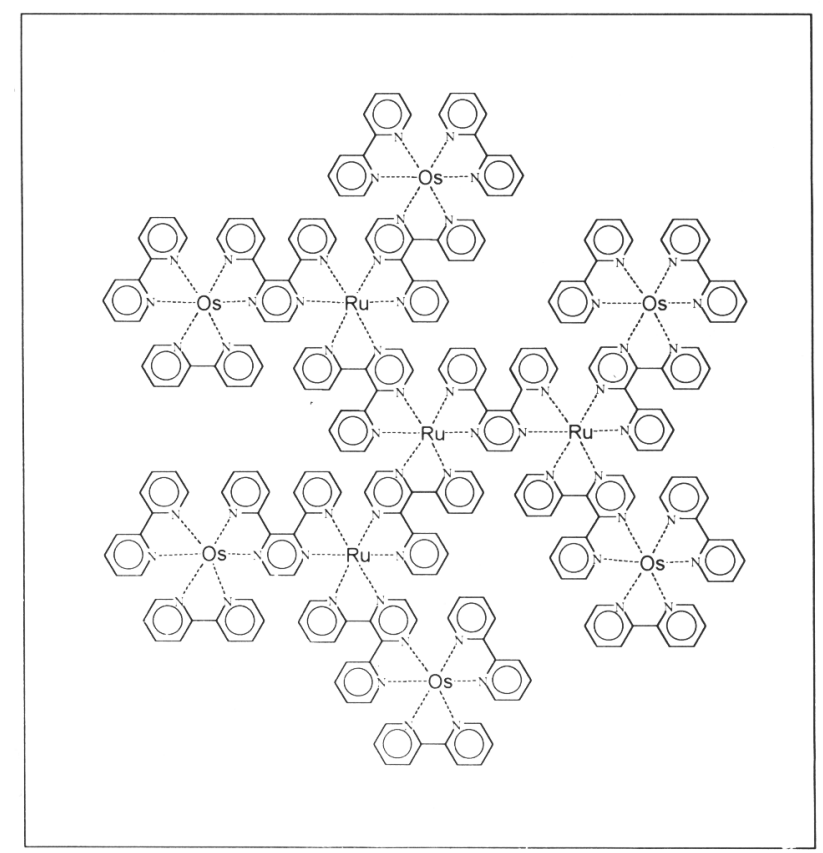

Figure 9. Decanuclear complex ("dendrimer") based on Ru and Os polypyridine units ${ }^{36}$.

via efficient intercomponent energy-transfer processes, from the center to the periphery of the complex, where it is re-emitted by the Os(II)-containing units as near-infrared luminescence ${ }^{37}$. Several other energy migration patterns can be obtained in similar decanuclear species, simply by using different combination of metals and ligands ${ }^{36}$.

This general synthetic approach can be extended toward larger dendrimers. Recently, a 22-nuclear arborol has been produced with $22 \mathrm{Ru}(\mathrm{II})$ centers $^{38}$. This species contains 1090 atoms (neglecting the counterions), has a 44+ overall charge, a relative molecular mass of 10890 , and an estimated size of about $5 \mathrm{~nm}$. Its absorption spectrum extends across the UV-visible spectral region, with extremely high intensity $(\varepsilon=202000$ $\mathrm{M}^{-1} \mathrm{~cm}^{-1}$ at $542 \mathrm{~nm}$ ). Emission occurs from the peripheral $\mathrm{Ru}-$ polypyridine units, indicating again efficient energy migration within the system ${ }^{38}$. Given the remarkable dimensions already reached, and the possibilities of further extension provided by the modular synthetic approach, this class of compounds seems to be very promising from the viewpoint of arriving at synthetic antenna systems comparable in light-harvesting efficiency to the natural ones.

For some practical purposes (e.g., to bind at an interface with good surface coverage) one-dimensional antenna systems might be more convenient than highly branched ones. A one-dimensional antenna requires stepwise energy transfer along a chain of molecular components, and the maximum length of the system (i.e., number of components) depends critically on the driving force demand of each energy-transfer step. The possibility to obtain efficient energy migration along chain-like systems has been checked with the cyano-bridged pentanuclear species shown in Figure $10 \mathrm{a}^{39}$. This complex contains a $\operatorname{Re}(\mathrm{I})$-based molecular component, three doubly-bridged $\mathrm{Ru}(\mathrm{II})$-based molecular components, and a terminal $\mathrm{Ru}(\mathrm{II})$-based molecular component, with all the bridging cyanides oriented in the same way ( $\mathrm{N}$-end pointing towards the terminal $\mathrm{Ru}(\mathrm{II})$ center). By molecular design, the relative MLCT excited-state energy ordering in this system is expected to be $\operatorname{Re}(\mathrm{I})>\mathrm{Ru}_{1}(\mathrm{II}) \approx \mathrm{Ru}_{2}$ (II) $\approx \mathrm{Ru}_{3}(\mathrm{II})>\mathrm{Ru}_{4}(\mathrm{II})$. Indeed, emission studies indicate that efficient energy transfer takes place from the $\operatorname{Re}(\mathrm{I})$-based unit, presumably through several steps involving the intermediate units, down to the terminal $\mathrm{Ru}(\mathrm{II})$-based unit $^{39}$. These results suggest that, in strongly coupled systems of this type, energy migration between isoenergetic adjacent molecular components takes placen efficiently. The presence of (i) a higher-energy "stopper" on one end and (ii) a lower-energy "trap" at the other end is sufficient to give directionality to the overall process. The same concept is developed in the "photonic wire" of Figure $10 b^{40}$, where excitation energy flows from the boron dipyrromethene unit, through the zinc porphyrins, to the free-base phophyrin molecular component. Thus, relatively long-chain one-dimensional antenna systems can be conceived following these general design principles.

\section{CONVERSION OF LIGHT INTO CHEMICAL ENERGY}

In the supramolecular systems discussed in section 3.1, part of the absorbed light energy is transiently stored as redox energy.

This energy can be converted in various ways. One, and perhaps the most important, possibility is that followed by Nature in photosynthesis, i.e., the use of this energy for production of high energy chemicals ("fuels"). Energy conversion by artificial photosynthesis is certainly one of the most challenging goals in chemistry, and in particular in supramolecular chemistry. Some of the basic principles involved are briefly discussed in this section.

From many points of view, the most attractive fuel-generating reaction is the cleavage of water into hydrogen and oxygen (eq. 2).

$1 / 2 \mathrm{H}_{2} \mathrm{O} \rightarrow 1 / 2 \mathrm{H}_{2}+1 / \mathrm{O}_{2}$

From the standard redox potentials of the two corresponding half-reactions, the free energy demand of eq. 2 is $1.23 \mathrm{eV}$. For many of the charge separated states discussed in section 3.1 , the difference in redox potentials of the oxidized and reduced molecular components is larger than this figure. Thus, light energy conversion by means of photoinduced charge separation as in Figure 5, followed by the reactions schematized by eqs. 3 and 4, is thermodynamically feasible using such systems.

$\mathrm{D}^{+}-\mathrm{P}-\mathrm{A}^{-}+\mathrm{H}_{2} \mathrm{O} \rightarrow \mathrm{D}^{+}-\mathrm{P}-\mathrm{A}+1 / 2 \mathrm{H}_{2}+\mathrm{OH}^{-}$

$\mathrm{D}^{+}-\mathrm{P}-\mathrm{A}+1 / 2 \mathrm{H}_{2} \mathrm{O} \rightarrow \mathrm{D}-\mathrm{P}-\mathrm{A}+1 / 4 \mathrm{O}_{2}+\mathrm{H}^{+}$ 


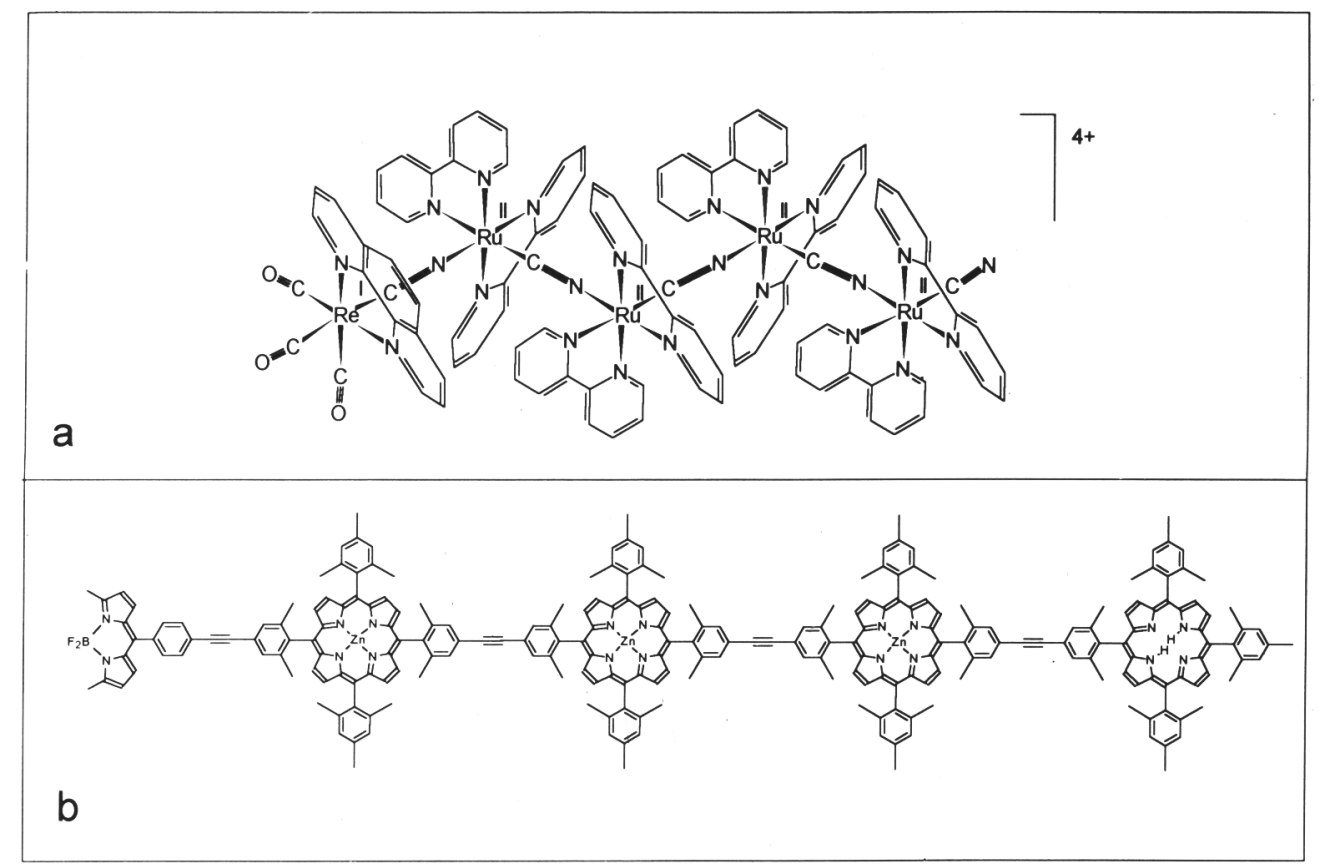

Figure 10. Examples of one-dimensional antenna systems: (a) pentanuclear cyano-bridged complex ${ }^{39}$; (b) porphyrin-based “photonic wire” 40.

None of these systems, however, would evolve hydrogen and oxygen upon ligth excitation in aqueous solution. This is due to a fundamental kinetic problem. The photoinduced charge separation is a one-electron process, and so is also the charge recombination process (eq. 5).

$\mathrm{D}^{+}-\mathrm{P}-\mathrm{A}^{-} \rightarrow$ D-P-A

On the other hand, reactions 3 and 4, written here in oneelectron terms for stoichiometric purposes, are actually multielectron processes (two electrons in the case of reaction 3 , four electrons in the case of reaction 4), and such reactions are inherently slow.

Thus, although relatively long-lived charge separation can be reached with supramolecular systems, reactions 3 and 4 would be hopelessly slow to compete with charge recombination (reaction 5). This problem is common to any conceivable fuel-generating processes.

The answer to this general problem lies in the possibility to accelerate multielectron redox reactions using catalysts. A catalyst for multielectron redox processes is essentially a "charge pool", that is, a species able to: (i) acquire electrons (or "holes") from a one-electron reducing (or oxidizing) species in a stepwise manner at constant potential; (ii) deliver these electrons (or "holes") to the substrate in a "concerted" way, so as to avoid the formation of high-energy intermediates. From the field of heterogeneous catalysis, metals and metal oxides are known be good candidates for this type of processes. From several studies on photochemical "water splitting" cycles ${ }^{41}$, colloidal platinum and colloidal $\mathrm{RuO}_{2}$ were identified as good catalysts for photochemical hydrogen and oxygen evolution, respectively.

Aside from solid-state materials, discrete supramolecular species can also be conceived as catalysts for multielectron redox reactions. This is what happens, for example, in green plant photosynthesis (Fig. 1), where an enzyme (still not wellcharacterized, but containing polynuclear manganese species ${ }^{1}$ ) catalyzes oxidation of water by the "hole" left on photosystem II. A supramolecular catalyst for multielectron redox processes must contain several equivalent redox centers (at least as many as the electrons to be exchanged), with the appropriate redox properties to mediate between the charge separated state and the substrate. The electronic coupling between such centers should be not too strong, otherwise the "charging" process (stepwise one-electron transfer to, or from, the catalyst) could not take place at a reasonably constant potential. On the other hand, the centers should be sufficiently close so as to be able to cooperate in binding and reducing, or oxidizing, the substrate. Although these requisites may not be easy to meet, the design of specific multielectron redox catalysts may be considered as a fascinating and challenging problem for supramolecular chemistry.

Any efficient artificial photosynthetic system must obey an additional requisite: to avoid uncontrolled energy-wasting back reactions, and to facilitate collection and storage, the products should be produced in physically separated compartments of the system. Therefore, as it occurs in the natural systems, some kind of "membrane" is needed to separate the oxidative and reductive part of the process. This, in turn, requires that every charge separating molecular device is specifically organized and oriented with respect to such a "membrane". This certainly represents a big step in additional complexity, which goes somewhat beyond supramolecular chemistry, extending into the rapidly growing fields of self-assembling processes and organized media ${ }^{42,43}$. The possibility to insert organic triads into bilipid membranes has already been verified ${ }^{44}$.

In summary, plausible artificial photosynthetic systems should include the following basic features, as schematized in Figure 11: (i) an antenna for light harvesting; (ii) a reaction center for charge separation; (iii) catalysts as one-to-multielectron interfaces between the charge separated state and the substrate; (iv) a membrane to provide physical separation of the products.

\section{CONVERSION OF LIGHT INTO ELECTRICAL ENERGY}

Another possibility to utilize ligth energy is to convert it directly into electricity. Photochemical generation of electricity is perhaps less ambitious than the production of chemical fuels, but is certainly much more likely as a short-term goal. This process is based on the use of photoexcitable molecules adsorbed onto the surface of a semiconductor.

Although the basic principles of dye sensitization of semiconductors have been established since long ${ }^{45,46}$, progress in 


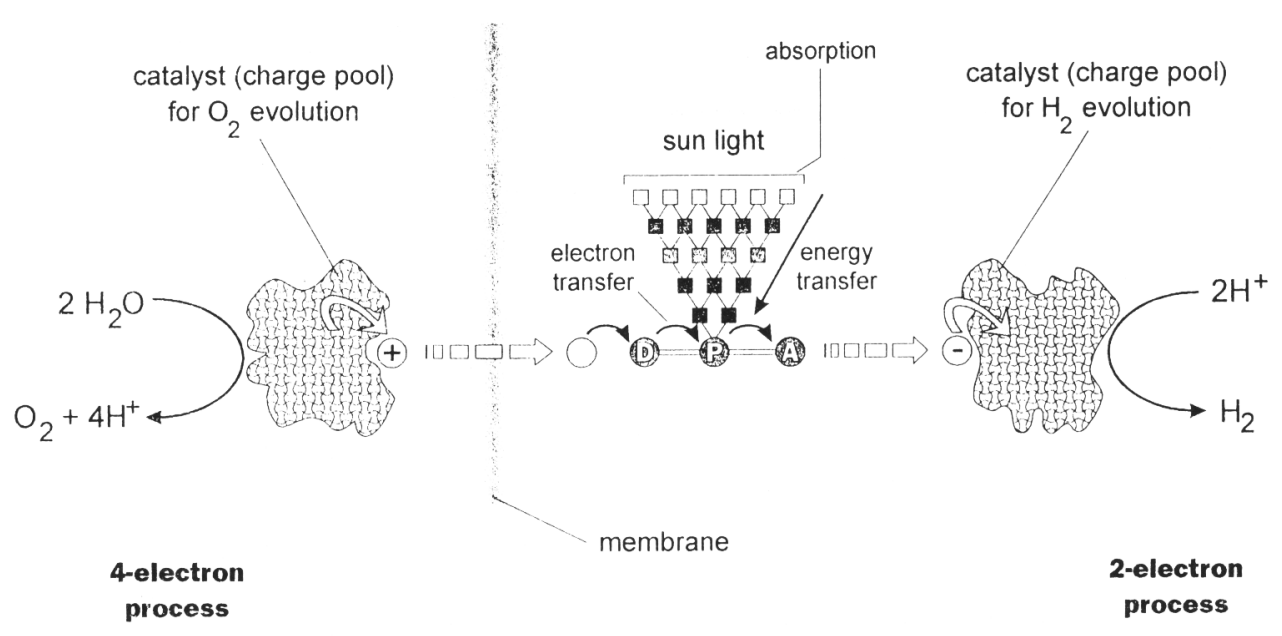

Figure 11. Basic features of a plausible artificial system for conversion of light energy into fuels ("artificial photosynthesis").

the application of such techniques to light energy conversion has been initially very slow. Very recently, however, the field has experienced a sharp acceleration, thanks to the development of new nanocrystalline semiconductor electrodes of very high surface area ${ }^{47-50}$. Based on such electrodes, efficient photoelectrochemical cells for the conversion of visible light energy into electricity have been constructed ${ }^{49}$. The basic steps taking place in a sensitized semiconductor cell are shown in Figure 12 . The system is constituted by a sensitizer chemically adsorbed onto the semiconductor surface, a solution containing a relay electrolyte, and a metallic counterelectrode. The sensitizer is first excited by light absorption. Then the excited sensitizer injects an electron into the conduction band of the semiconductor (process 1 in Fig. 12). The oxidized sensitizer is reduced by a relay molecule (process 2 in Fig. 12), which then diffuses to discharge at the counterelectrode (process 3 in Fig. 12). As a result, a photopotential is generated between the two electrodes in open circuit conditions, and a corresponding photocurrent can be obtained upon closing the external circuit through an appropriate load.

A real cell of this type (Fig. 13) looks as a colored transparent glass sandwhich. Everything takes place in the thin space $(50-100 \mu \mathrm{m})$ between two conducting glasses: the semiconductor is titanium dioxide, deposited as a thin nanocrystalline layer on one of the glasses; the sensitizer is a $\mathrm{Ru}(\mathrm{II})$-polypyridine complex grafted to the $\mathrm{TiO}_{2}$ surface via carboxylate functions; the relay redox couple is iodine/iodide in an appropriate phase; the counterelectrode is a platinized area on the other glass. With state-of-the-art materials, open-circuit photovoltages of ca. $0.6 \mathrm{~V}$, short-circuit photocurrents of about $8-10 \mathrm{~mA} / \mathrm{cm}^{2}$, and overall solar energy conversion efficiencies of the order of $7-10 \%$ can be obtained in laboratory experiments. Development at the industrial level is now being attempted in several countries, the benchmark for competition being the well-established silicon-based photovoltaic devices.

This cell might look at first sight quite different from the photosynthetic systems discussed so far. On closer inspection, however, analogies do appear. The system is clearly based on photoinduced charge separation. From this viewpoint, one can consider the system as a "pseudo-triad" similar to that of Figure 5, where the semiconductor surface acts as the primary acceptor and the relay as the secondary donor. As in any triad, the efficiency of charge separation and energy conversion will depend critically on the kinetic competition between the various forward processes and charge recombination steps. The main difference with photosynthetic systems is simply that the redox potential energy of the

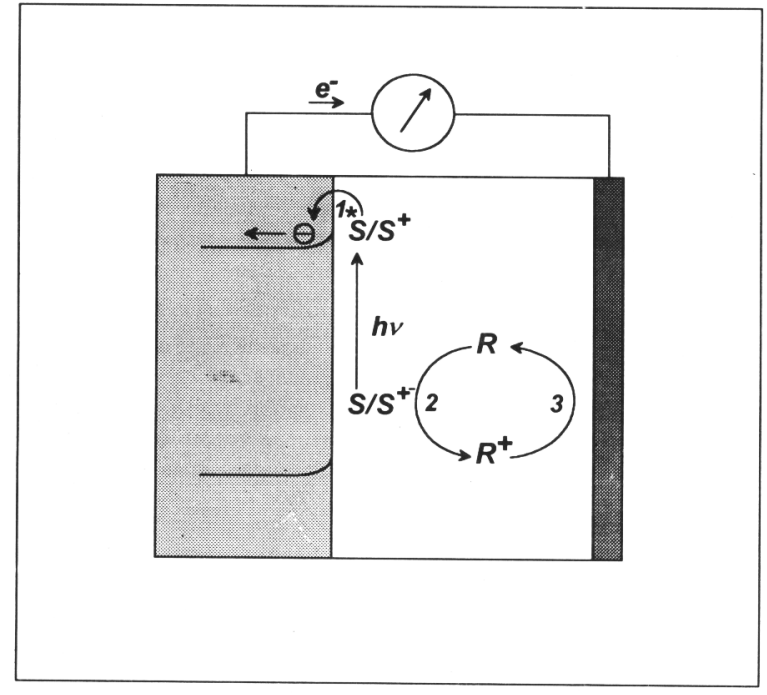

Figure 12. Working principle of a photosensitized (n-type) semiconductor cell.

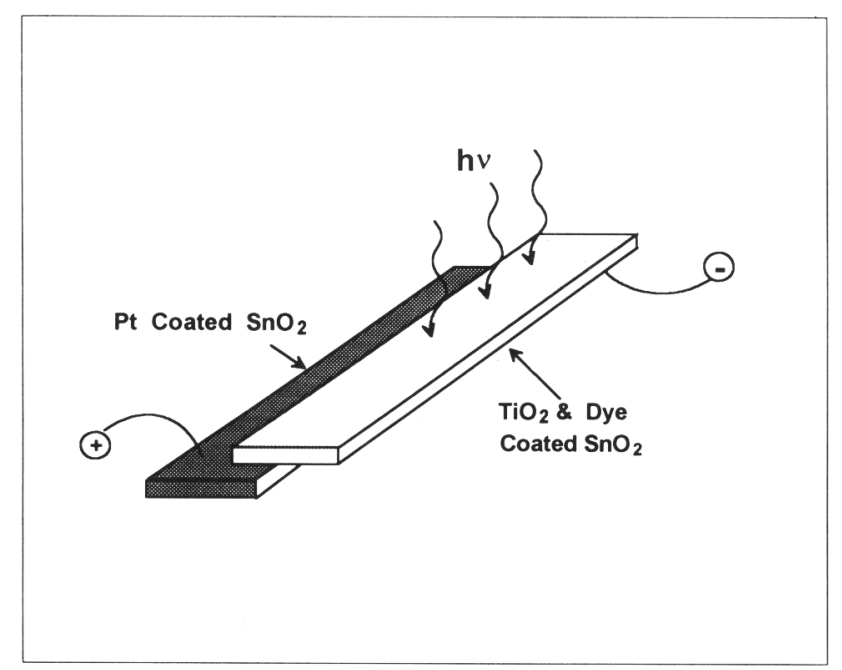

Figure 13. Practical sensitized semiconductor cell for conversion of light energy into electricity. 
"charge separated state" is not stored in products of subsequent reactions, but rather it is directly used to produce a photocurrent.

Taking this comparative analysis a step further, one could think of applying some of the strategies of photosynthesis to increase the efficiency of these photoelectrochemical cells ${ }^{51}$. For instance, just as it is done in going from triads to tetrads, pentads etc. (Fig.6), it is conceivable that an increase in the number of steps in the charge separation sequence could improve the efficiency of the cell. Also, the antenna effect could find some useful application in such systems. In the standard cell design, the problem of light harvesting is solved by the use of nanostructured $\mathrm{TiO}_{2}$ of exceptionally high surface area: a very large number of photosensitizer molecules can lie on the semiconductor surface and each molecule is responsible for both light absorption and charge separation. In principle, high light-harvesting efficiencies could be obtained with a flatter $\mathrm{TiO}_{2}$ surface if the sensitizer molecule at the semiconductor-solution interphase with an antenna-sensitizer molecular device ${ }^{52}$. Such a device should take advantage of efficient intercomponent energy transfer from a number of "antenna" chromophoric units to a specific chromophoric unit, which behaves at the same time as an energy collector and as a charge injection sensitizer. In this way, the light energy absorbed by all the chromophoric components can be used to effect charge injection, with an increase in the overall cross-section for light absorption compared to the case of a simple molecular sensitizer. As a further advantage, an appropriate selection of the spectral properties of the antenna and sensitizer chromophores can lead to better matching between absorption spectrum and solar emission spectrum. These features have been demonstrated using the trinuclear complex $\left[\mathrm{Ru}(\mathrm{bpy})_{2}(\mathrm{CN})_{2}\right]_{2}-\mathrm{Ru}\left(\text { bpy- }(\mathrm{COO})_{2}\right)_{2}{ }^{2-}$ (Fig. 14) as antenna-sensitizer molecular device on $\mathrm{TiO}_{2}$-coated electrodes ${ }^{52}$. The same

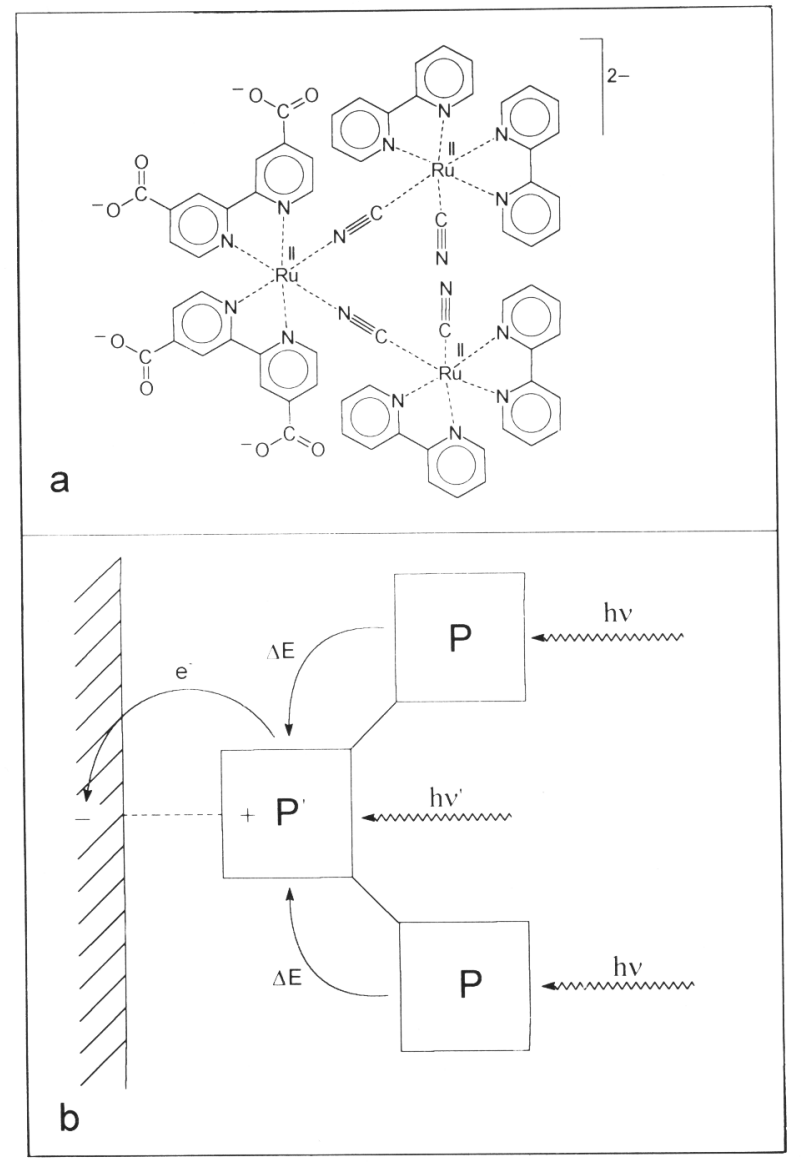

Figure 14. Trinuclear antenna-sensitizer molecular device (a) and behavior on the semiconductor surface $(b)^{52}$. trinuclear complex gives remarkably high efficiencies of conversion in nanocrystalline $\mathrm{TiO}_{2}$ cells ${ }^{49}$. The idea of applying the antenna effect in the sensitization of semiconductors can be extended towards larger systems. Several well characterized systems of high nuclearity, e.g., porphyrin arrays, dendrimers, and the chain-like cyano-bridged complexes (section 3.2, Figs. 810 ), could be used as the light harvesting portion in antennasensitizer molecular devices.

\section{CONCLUSION}

Conversion of solar energy into more useful energy sources is one of the central problems of modern chemistry ${ }^{3}$. From a practical standpoint, it hits the heart of the energy problem, so relevant to our future in terms of the possibilities to sustain development and civilization. From a scientific point of view, it constitutes a fascinating subject, lying at the crossroads of many important disciplines, such as chemical synthesis, kinetics, spectroscopy, photochemistry, electrochemistry, biochemistry, and material science.

An effective approach to this ambitious goal conjugates (i) the understanding of the fundamental mechanisms of natural energy-conversion systems and (ii) the use of advanced synthetic methods, new materials, and frontier experimental techniques in the development of artificial systems. Research along these lines is active in many laboratories around the world, with remarkable progress being made in various directions. While the conversion of solar energy into fuels ("artificial photosynthesis") is still probably to be regarded as a long term objective, the conversion into electricity with semiconductorbased photoelectrochemical cells is rapidly reaching the stage of practical application. Ciamician's vision ${ }^{54}$ whereby

"On the arid lands there will spring up industrial colonies without smoke and without smokestacks; forests of glass tubes will extend over the plains and glass buildings will rise everywhere; inside of these will take place the photochemical processes that hitherto have been the guarded secret of the plants, but that will have been mastered by human industry which will know how to make them bear even more abundant fruit than nature, for nature is not in a hurry but mankind is"

looks now much less of a dream than it did eighty-three years ago.

\section{REFERENCES}

1. Häder, D.-P.; Tevini, M.; General Photobiology, Pergamon Press, Oxford, 1987.

2. Deisenhofer, J.; Epp, O.; Miki, K.; Huber, R.; Michel, H.; J. Mol. Biol. 1984, 180, 385.

3. Chang, C.-H.; Tiede, D. M.; Tang, J.; Smith, U.; Norris, J.; Schiffer, M.; FEBS Lett. 1986, 205, 82.

4. Allen, J. P.; Feher, G.; Yeates, T. O.; Komiya, H.; Rees, D. C.; Proc. Natl. Acad. Sci. USA 1987, 84, 5730.

5. Deisenhofer, J.; Michel, H.; Angew. Chem. Int. Ed. Engl. 1989, $28,829$.

6. Huber, R.; Angew. Chem. Int. Ed. Engl. 1989, $28,848$.

7. Bixon, M.; Jortner, J.; Michel-Beyerle, M. E.; Orgodnik, A.; Lersch, W.; Chem. Phys. Lett. 1987, 140, 626.

8. Marcus, R. A.; Chem. Phys. Lett. 1987, 133, 471.

9. Fleming, G. R.; Martin, J. L.; Breton, J.; Nature 1988, $333,190$.

10. Moser, C. C.; Alegria, G.; Gunner, M. R.; Dutton, P. L.; in Photochemical energy conversion, eds J. R. Jr. Norris and D. Meisel, Elsevier, 1989, p. 221.

11. Holzapfel, W.; Finkele, U.; Kaiser, W.; Oesterhelt, D.; Scheer, H.; Stilz, H. U.; Zinth, W.; Chem. Phys. Lett. 1989, $160,1$. 
12. Dressler, K.; Umlauf, E.; Schmidt, S.; Hamm, P.; Zinth, W.; Buchanan, S.; Michel, H.; Chem. Phys. Lett. 1991, 183,270

13. Hammerstad-Pedersen, J. M.; Jensen, M. H.; Kharkats, Y. I.; Kuznetsov, A. K.; Ulstrup, J.; Chem. Phys. Lett. 1993, 205, 591.

14. Kirmaier, C.; Holten, D.; Parson, W. W.; Biochim. Biophys. Acta 1985, 810, 33.

15. Holten, D.; Windsor, M. W.; Parson, W. W.; Thornber, J. P.; Biochim. Biophys. Acta 1978, 501, 112.

16. Marcus, R. A.; Annu. Rev. Phys. Chem. 1964, 15, 155.

17. Jortner, J.; J. Chem. Phys. 1976, 64, 4860.

18. Ulstrup, J.; Charge Transfer Processes in Condensed Media, Springer:Verlag, 1979.

19. Sutin, N.; Prog. Inorg. Chem. 1983, 30, 441.

20. Marcus, R. A.; Sutin, N.; Biochim. Biophys. Acta 1985, $811,265$.

21. McDermott, G.; Prince, S. M.; Freer, A. A.; Hawthornthwaite-Lawless, A. M.; Papiz, M. Z.; Cogdell, R. J.; Isaacs, N. W.; Nature 1995, 374, 517.

22. Kuhlbrandt, W.; Nature 1995, 374, 497.

23. Karrasch, S.; Bullough, P. A.; Ghosh, R.; EMBO J. 1995, 14,631 .

24. Kuhlbrandt, W.; Wang, D. N.; Fujiyoshi, Y.; Nature 1994, 367, 1994.

25. Balzani, V.; Scandola, F.; Supramolecular Photochemistry, Horwood,Chichester, 1991, Chapter 5.

26. Wasielewski, M. R.; Chem. Rev. 1992, 92, 435.

27. Paddon-Row, M. N.; Acc. Chem. Res. 1994, 27, 18.

28. Larson, S. L.; Cooley, L. F.; Elliott, C. M.; Kelley, D. K.; J. Am. Chem. Soc. 1992, 114, 9504.

29. Mecklenburg, S. L.; Peek, B. M.; Schoonover, J. R.; McCafferty, D. G.; Wall, C. G.; Erickson, B. W.; Meyer, T. J.; J. Am. Chem. Soc. 1993, 115, 5479.

30. Chambron, J.-C.; Coudret, C.; Collin, J.-P.; Guillerez, S.; Sauvage, J.-P.; Barigelletti, F.; Balzani, V.; De Cola, L.; Flamigni, L.; Chem. Rev. 1994, 94, 993.

31. Moore, T. A.; Gust, D.; Mathis, P.; Mialocq, J. C.; Chachaty, C.; Bensasson, R. V.; Land, E. J.; Doizi, D.; Liddell, P. A.; Nemeth, G. A.; Moore, A. L.; Nature 1984, 307, 630.

32. Gust, D.; Moore, T. A.; Science 1989, 244, 35.

33. Gust, D.; Moore, T. A.; Moore, A. L.; Acc. Chem. Res. 1993, 26, 198.

34. Balzani, V.; Scandola, F.; Supramolecular Photochemistry,
Horwood, Chichester 1991, Chapter 12.

35. Prathapan, S.; Johnson, T. E.; Lindsey, J. S.; J. Am. Chem. Soc. 1993, 115, 7519.

36. Denti, G.; Campagna, S.; Serroni, S.; Ciano, M.; Balzani, V.; J. Am. Chem. Soc. 1992, 114, 2944.

37. Juris, A.; Balzani, V.; Campagna, S.; Denti, G.; Serroni, S.; Frei, G.; Güdel, H.; Inorg. Chem. 1994, 33, 1491.

38. Serroni, S.; Denti, G.; Campagna, S.; Juris, A.; Ciano, M.; Balzani, V.; Angew. Chem. Int., Ed. Engl. 1992, 31, 1493; Campagna, S.; Denti, G.; Serroni, S.; Juris, A.; Venturi, M.; Ricevuto, V.; Balzani, V.; Chem. Eur. J. 1995, $1,211$.

39. Bignozzi, C. A.; Argazzi, R.; Chiorboli, C.; Scandola, F.; Dyer, R. B.; Schoonover, J. R.; Meyer, T. J.; Inorg. Chem. 1994, 33, 1652.

40. Wagner, R. W.; Lindsey, J. S.; J. Am. Chem. Soc. 1994, $116,9759$.

41. Grätzel, M.; ed. Energy resources through photochemistry and catalysis, Academic Press, New York, 1983.

42. Whitesides, G. M.; Mathias, J. P.; Seto, C. T.; Science 1991, 254, 1312.

43. Ringsdorf, H.; Schlarb, B.; Venzmer J.; Angew. Chem. Int. Ed. Engl. 1988, 27, 113.

44. Seta, P.; Bienvenue, E.; Moore, A. L.; Mathis, P.; Liddell, P.; Passiki, P. J.; Joy, A.; Moore, T. A.; Gust, D.; Nature 1985, 316, 653.

45. Gerischer, H.; Willig, F.; Topics Curr. Chem. 1976, 61, 31 46. Memming, R.; Prog. Surface Sci. 1984, 17, 7.

47. Desilvestro, J.; Grätzel, M.; Kavan, L.; Moser, J.; J. Am. Chem. Soc. 1985, 107, 2988.

48. Vlachopoulos, N.; Liska, P.; Augustynski, J.; Grätzel, M.; J. Am. Chem. Soc. 1988, 110, 1216.

49. O'Regan, B.; Grätzel, M.; Nature 1991, 353, 737.

50. (a) Grätzel, M.; Comments Inorg. Chem. 1991, 12, 93. (b) Grätzel, M.; In: Photosensitization and Photocatalysis Using Inorganic and Organometallic Compounds; Kalyanasundaram, K.; Grätzel, M.; Eds; Kluwer, Dordrecht 1993, p. 247.

51. Bignozzi, C. A.; Schoonover, J. R.; Scandola, F.; Prog. Inorg. Chem. in press.

52. Amadelli, R.; Argazzi, R.; Bignozzi, C.A.; Scandola, F.; J. Am. Chem. Soc. 1990, 112, 7099.

53. Bard, A. J.; Fox, M. A.; Acc. Chem. Res. 1995, 28, 141.

54. Ciamician, G.; Science 1912, 36, 385. 